\title{
Using impact assessment methods to determine the effects of a marine reserve on abundances and sizes of valuable tropical invertebrates
}

\author{
M.P. Lincoln-Smith, K.A. Pitt, J.D. Bell, and B.D. Mapstone
}

\begin{abstract}
Procedures for impact assessment, including "beyond-BACI" (before-after control-impact) and proportional differences (ratios between impact and control treatments) were used to test population replenishment of marine invertebrates at a marine conservation area (MCA) and three fished (control) areas in the Solomon Islands of the southwestern tropical Pacific. Within shallow reef terrace habitat, the MCA caused abundance and size of the topshell Trochus niloticus to increase but did not affect holothurians (sea cucumbers) or the giant clam Tridacna maxima. Abundance of the nonexploited topshell Tectus pyramis was unchanged at the MCA but increased at the controls, possibly because of changes in abundance of T. niloticus. Within deep slope habitat, the MCA caused increased abundance of the sea cucumber Holothuria fuscogilva and prevented possible declines in abundances of Thelanota anax and all holothurians combined but had no effect on abundances of Holothuria atra or Holothuria fuscopunctata. Power analysis comparing the MCA with controls indicated that further, relatively modest increases in abundance or size of some species would have a good chance of being detected statistically. The beyond-BACI procedure holds promise for enabling rigorous evaluation of marine reserves as management tools at different spatial scales; the use of proportional differences is simpler but has limited management value.
\end{abstract}

Résumé : Des procédures d'évaluation des impacts, dont l'au-delà du BACI (« beyond-BACI »; avant-après témoinimpact) et des différences proportionnelles (rapports entre les conditions d'impact et les conditions témoins) nous ont servi à vérifier le renflouage des populations d'invertébrés marins dans une zone de conservation marine (MCA) et trois régions soumises à la pêche (témoins) dans les îles Salomon, sud-ouest du Pacifique tropical. Dans les habitats de récifs en terrasse de faible profondeur, la MCA cause un accroissement de l'abondance et de la taille du trocha, Trochus niloticus, mais n'affecte pas les holothuries (concombres de mer) ou la moule géante, Tridacna maxima. L'abondance du troca blanc, Tectus pyramis, non exploité reste inchangée dans les MCA, mais augmente dans les zones témoins, peut-être à cause des changements d'abondance de T. niloticus. Dans les habitats de pente profonds, la MCA a accru l'abondance du concombre de mer Holothuria fuscogilva, a empêché les déclins potentiels d'abondance de Thelanota anax et de toutes les holothuries combinées, mais est restée sans effet sur les abondances d'Holothuria atra ou d'Holothuria fuscopunctata. Une analyse de puissance qui compare la MCA aux zones témoins indique que des accroissements futurs relativement modestes d'abondance ou de taille de certaines espèces auraient de bonnes chances d'être détectées statistiquement. La méthode d'au-delà du BACI est prometteuse comme outil de gestion pour l'évaluation rigoureuse des réserves marines à différentes échelles spatiales; l'utilisation des différences proportionnelles est plus simple, mais elle possède une valeur limitée pour la gestion.

[Traduit par la Rédaction]

\section{Introduction}

Marine reserves have been advocated as a tool for managing fisheries resources (Roberts and Polunin 1993; Tegner 1993; Bohnsack 1998), particularly in tropical regions where conventional fisheries management theory and practice have been generally unsuccessful in sustaining complex, multispecies reef fisheries (Roberts and Polunin 1993). The potential benefits claimed for reserves include increases in abundance and size of individuals, increased diversity of

Received 15 April 2005. Accepted 24 January 2006. Published on the NRC Research Press Web site at http://cjfas.nrc.ca on 26 April 2006.

$\mathrm{J} 18654$

M.P. Lincoln-Smith. ${ }^{1}$ The Ecology Lab Pty Ltd., 4 Green Street, Brookvale, New South Wales 2100, Australia.

K.A. Pitt. Centre for Aquatic Processes and Pollution and School of Environmental and Applied Science, Griffith University, PMB 50, Gold Coast Mail Centre, Queensland 9726, Australia, and The Ecology Lab Pty Ltd., 4 Green Street, Brookvale, New South Wales 2100, Australia.

J.D. Bell. The WorldFish Center, P.O. Box 500, GPO, 10670 Penang, Malaysia.

B.D. Mapstone. Antarctic Climate and Ecosystems Cooperative Research Centre, Private Bag 80, University of Tasmania, Hobart, Tasmania, 7001, Australia.

${ }^{1}$ Corresponding author (e-mail: mls@theecologylab.com.au). 
species, and emigration of juveniles and adults or export of propagules to areas outside the reserve (Roberts and Polunin 1991; Dugan and Davis 1993; Bohnsack 1998). Although there are strong theoretical arguments in support of these benefits, data from field experiments have often been equivocal (Russ 2002; Willis et al. 2003; Sale et al. 2005; but see McClanahan and Arthur 2001). There is a pressing need to test the effectiveness of marine reserves for managing fisheries because the economic, social, and cultural costs associated with establishing and managing reserves can be considerable (Bergin 1993; Parrish 1999; Hilborn et al. 2004). Sound assessments will empower managers to decide whether marine reserves are the best way to use the often limited resources available to them for regulating fishing. A caveat here is that even where marine reserves are deemed to be an appropriate tool, they will be effective only if there is minimal illegal harvesting within the reserve. This requires the co-operation of local communities, especially in situations where organized enforcement of reserves is scarce or lacking.

An evaluation of a marine reserve requires separation of the effects of the reserve from natural spatial and temporal heterogeneity (Garcia-Charton and Perez-Ruzafa 1999). Specifically, increases in abundance or size of target species of interest within the reserve from before to after establishment of the reserve must exceed natural temporal fluctuations outside the reserve where harvest is occurring. Also, differences between the reserve and control (fished) areas must exceed natural variation among control areas. This requires sampling within the reserve, and at multiple control areas, several times before and after establishment of the reserve. This approach is known as a "beyond-BACI" (before-after control-impact) sampling design and was developed to assess environmental impacts when the affected location was unreplicated (Underwood 1993). With few exceptions (e.g., Edgar and Barrett 1997; Schroeter et al. 2001), sampling protocols for impact assessment have rarely been applied to assessments of marine reserves, although their use has been advocated (Carr and Reed 1993; Lincoln-Smith et al. 1997; Russ 2002).

The development of methods for measuring environmental impacts has been active since the 1970s. Eberhardt (1976) noted that essential inferences in modern experimental design rely on random assignment of experimental "treatments" and "controls", but many environmental impacts occur at a specific single location, and therefore, the impact treatment cannot be selected at random from an assortment of possible locations. Most studies of environmental impact are limited to one impacted area. Moreover, although one or more control areas may be available, randomization generally applies only to subsampling (Eberhardt 1976; StewartOaten and Bence 2001). Beyond-BACI assumes that the location of a putative impact is selected randomly in terms of environmental indicators. That is not to say that social, economic, or logistical reasons for selecting that location are also random. In fact, they generally are not. This distinction has lead, in part, to debate regarding the suitability of beyond-BACI (Stewart-Oaten and Bence 2001; but see Keough and Mapstone 1997). Despite this debate, beyondBACI has been applied in impact studies (e.g., Roberts et al. 1998). One alternative approach advocated has been to com- pare the difference ("delta" values) between impact and control locations as time series before and after the onset of the impact using a $t$ test, which also facilitates simple calculation of statistical power (Schroeter et al. 1993; Osenberg et al. 1994).

The $83 \mathrm{~km}^{2}$ Arnavon Islands Marine Conservation Area (MCA) was established in the Solomon Islands in 1995. Apart from Conservation Officers, no one lives on the Arnavon Islands. The islands were accessed before closure by boats from neighbouring villages. Three aspects of the Arnavon Islands MCA enabled testing of some of the anticipated benefits of marine reserves. First, surveys could be done at several spatial scales in the MCA and at several control locations before and after declaration of the MCA. Second, several species of invertebrates were harvested heavily throughout the Solomon Islands (Richards et al. 1994). Third, the MCA was established with the support of local communities.

The MCA was also suitable for applying the beyondBACI design. Habitats and initial observations of species were similar to those in many other places within the general area. Thus, although selection of the MCA was not random for social reasons, it was reasonable to assume randomness for the performance indicators selected (i.e., abundance and size of commercially exploited invertebrates). Moreover, the ubiquitous nature of the habitat within the vicinity of the MCA provided ample opportunity to select control areas. Finally, there was time available (albeit limited) to do baseline surveys before the declaration of the reserve.

The major objective of this study was to test the hypothesis that the number and size of commercially exploited invertebrates would increase at the Arnavon Islands relative to fished areas nearby after establishment of the MCA. The hypothesis regarding increases in sizes was based on the assumption that fishers had previously targeted, or collected with greater efficiency, large individuals, although lower and upper size limits of 7 and $11 \mathrm{~cm}$ applied to one species, Trochus niloticus.

\section{Materials and methods}

\section{Estimating changes in abundance}

Invertebrates were sampled at four island groups (Arnavon, Waghena, Ysabel, and Suavanao; Fig. 1). The MCA was established at the Arnavon Islands in August 1995 and the remaining groups were controls. The number of control groups and sampling procedures were determined by pilot studies (Lincoln-Smith et al. 1997). Two islands were sampled in each group, and at each island, four sites were sampled within each of two habitats: shallow reef terrace habitat (depth range 0.5-3.5 m) and deeper sand and rubble slope habitat $(15-22 \mathrm{~m})$. Sites encompassed 5-10 ha and the same sites were sampled each time. Sites were selected in consultation with the local community and included only if the community had previously harvested target species there. Two habitats were sampled because trochus and giant clams were generally restricted to shallow reef terrace habitat, but several species of holothurians were more abundant in either of the two habitats. Invertebrates were counted by divers within six $50 \mathrm{~m}$ transects randomized within each site during 
Fig. 1. Location of $(a)$ the Arnavon Islands Marine Conservation Area in the Solomon Islands and $(b)$ the three control locations, Waghena, Ysabel and Suavanao.
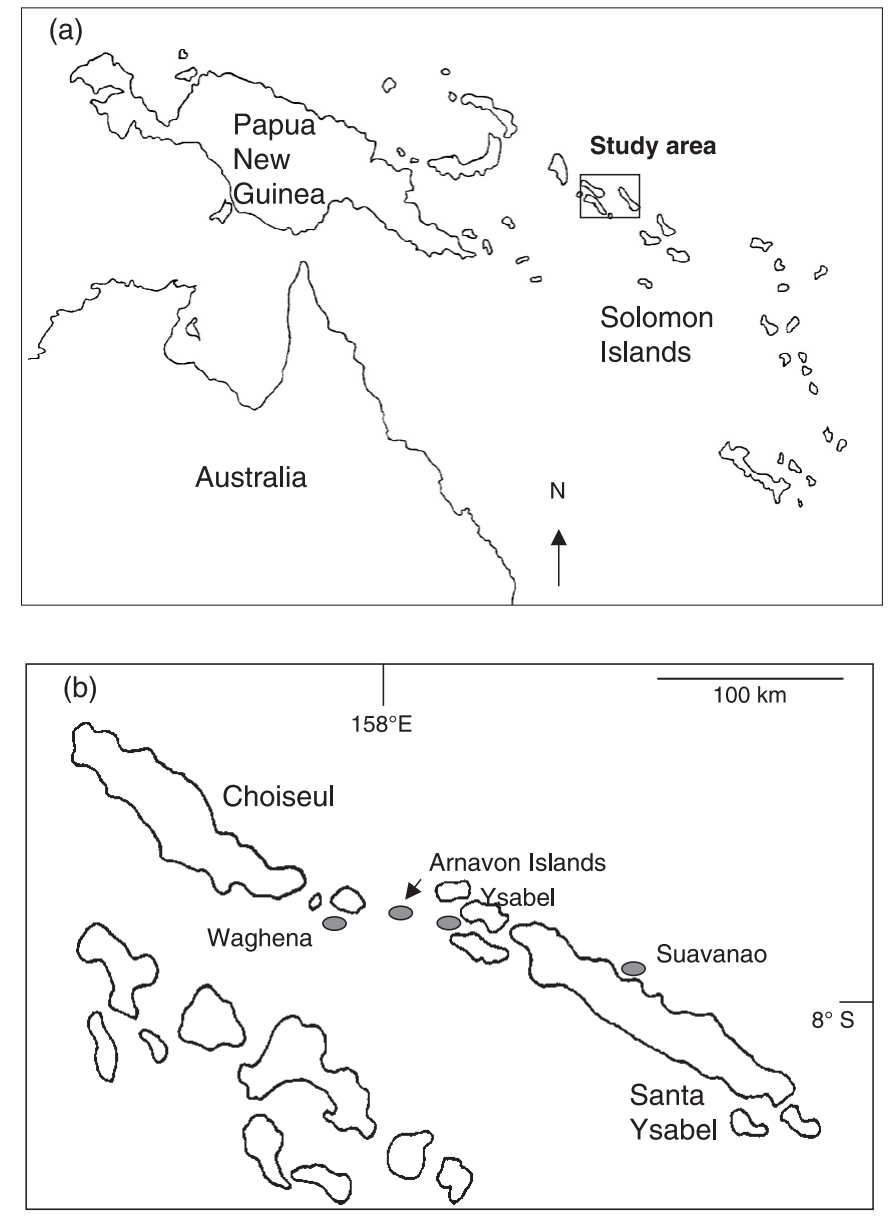

each survey. Transects were $2 \mathrm{~m}$ and $5 \mathrm{~m}$ wide in the terrace and slope habitats, respectively.

The MCA was declared in August 1995. Time was made available by local communities for us to do three surveys before and three surveys after closure: January-February, April-May, and July-August 1995 (before); and September 1998, January-February 1999, and April 1999 (after).

\section{Analysis of abundance data using beyond-BACI}

Variation in abundance was examined using five-factor beyond-BACI analyses of variance (ANOVA) (Underwood 1992, 1993). The model statement for the design is

$$
\begin{aligned}
X_{i j k l m n} & =\mu+\mathrm{B}_{i}+\mathrm{T}(\mathrm{B})_{i(j)}+\mathrm{G}_{k}+\mathrm{I}(\mathrm{G})_{l(k)} \\
& +\mathrm{S}(\mathrm{I}(\mathrm{G}))_{m(l(k))}+\mathrm{BG}_{i k}+\mathrm{BI}(\mathrm{G})_{i l(k)} \\
& +\mathrm{BS}(\mathrm{I}(\mathrm{G}))_{i m(l(k))}+\mathrm{T}(\mathrm{B}) \mathrm{G}_{i(j) k} \\
& +\mathrm{T}(\mathrm{B}) \mathrm{I}(\mathrm{G})_{i(j) l(k)}+\mathrm{T}(\mathrm{B}) \mathrm{S}(\mathrm{I}(\mathrm{G}))_{i(j) m(l(k))} \\
& +\varepsilon_{n(m i j k l)}
\end{aligned}
$$

where $X_{i j k l m n}$ is the value of any one datum made up of the overall mean $(\mu)$, residual (unexplained) variance $\left(\varepsilon_{n(m i j k l)}\right)$, and contributions of the five factors and their statistical interactions: ( $i$ ) before vs. after (B); (ii) times (T(B)), which were nested within before vs. after and included the three "before" and three "after" surveys; (iii) groups (G), which included an asymmetrical comparison of the Arnavon group with the three control groups; (iv) islands $(\mathrm{I}(\mathrm{G}))$, which were nested within groups; and $(v)$ sites $(\mathrm{S}(\mathrm{I}(\mathrm{G})))$, which were nested within islands and groups. Other terms in the model were interactions. Before vs. after was a fixed factor. Times, groups, islands, and sites were random factors. Groups were treated as random because it was assumed that the habitats in which the species were sampled were representative subsamples of the region with no particular biases attributable to particular groups. Thus, even though the selection of the Arnavon Islands as a reserve was based largely on social considerations, habitats in that group were no different a priori than the same habitats in the other groups. Data from the two habitats were analysed separately because of the different methods used to sample each habitat.

The spatial factors in the model were orthogonal with respect to the temporal factors because the same groups, islands, and sites were sampled at each time, but different transects were sampled at each site at each time. The alternative of selecting new sites at random for each survey was not available because not enough sites were present at the MCA. In such cases, an alternative model would be to use repeated measures analyses (e.g., Green 1993; Keough and Mapstone 1997) with sites as the basic sampling unit, but given the small size of transects compared with the area of each site, the beyond-BACI approach was considered suitable.

Underwood $(1992,1993)$ described the mechanics of conducting asymmetrical ANOVAs. The sequence of tests required to detect a change varies depending on the results of initial tests. Two-tailed $F$ tests were sometimes required, subsequent to initial tests, because temporal variation occurred at both the MCA and control areas after the establishment of the MCA. An impact could be identified by using a two-tailed test to compare the magnitude of variation within the MCA and control areas before and after establishment of the MCA (Underwood 1993). Similarly, if changes were identified from before to after establishment at the MCA and the controls, two-tailed tests were required to compare the magnitude of changes between the MCA and control areas. No tests were available for some factors, but tests were sometimes created by eliminating interaction terms that were nonsignificant at $P \geq 0.25$ (Underwood 1997). Cochran's $C$ tests were used to test the assumption of homogeneity of variances, and data were transformed to $\ln (x+1)$ where necessary to satisfy the assumption of homoscedasticity. However, if transformation failed to stabilize variances, raw data were analysed because ANOVA is robust to the assumption of homogeneous variances, particularly when the sampling design is balanced and has large numbers of replicates and treatments (Underwood 1997), as was the case here. Sometimes $\alpha$ is reduced to 0.01 when analyzing heteroscedastic data to control the probability of making a type I error because of heterogeneous variances. Reducing $\alpha$, however, increases the potential for type II errors (Mapstone 1995; Underwood 1997). We retained $\alpha$ at 0.05, therefore, despite the potential for elevated risk of committing a type I error (i.e., concluding that the MCA had an effect when, in fact, it did not) in preference to increasing the likelihood of erroneously concluding that the MCA had no effect, when it actu- 
Table 1. Asymmetrical analysis of variance comparing abundance of Trochus niloticus between the Arnavon Islands and reference locations, before and after declaration of the marine conservation area at the Arnavon Islands (MCA).

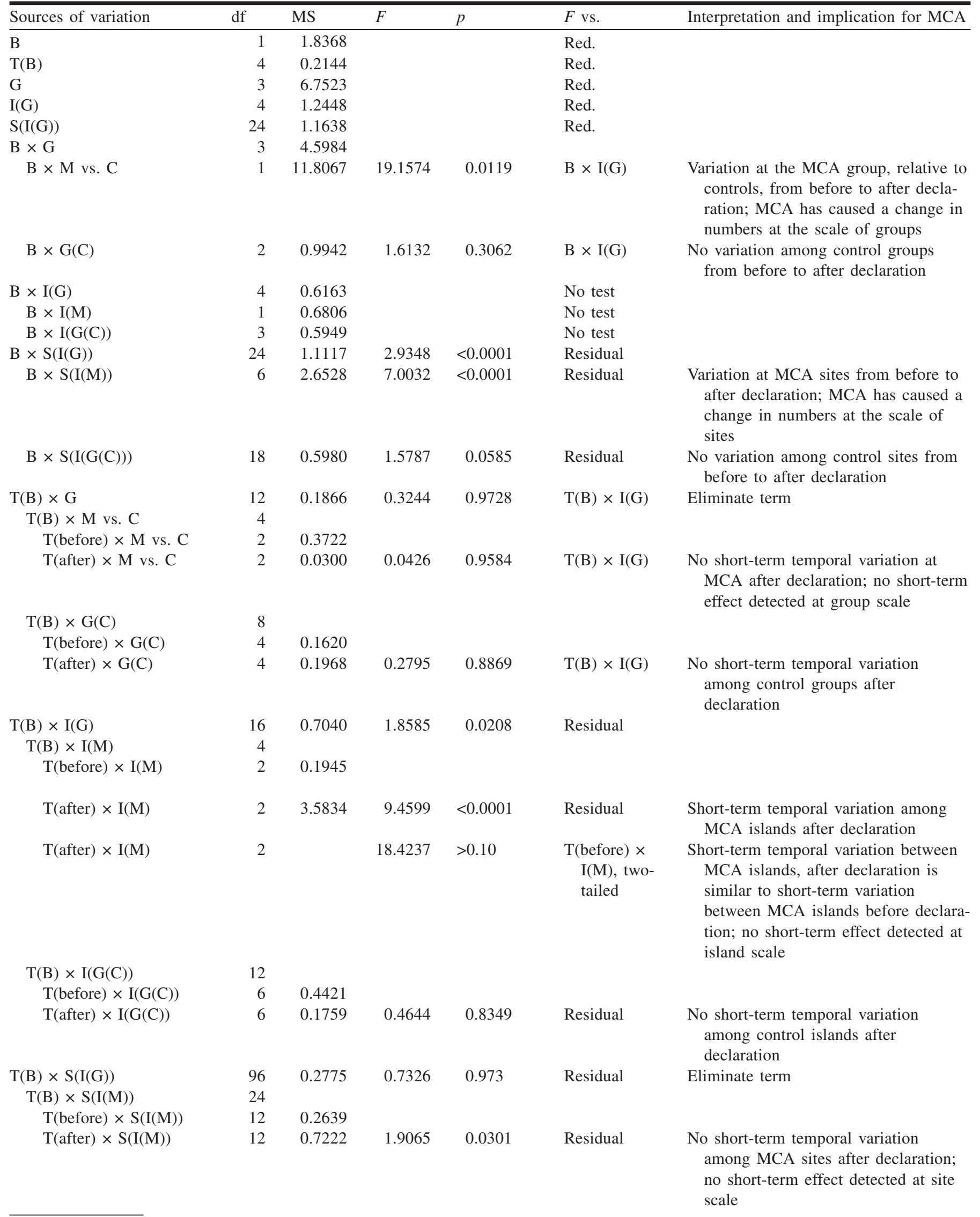


Table 1 (concluded).

\begin{tabular}{|c|c|c|c|c|c|c|}
\hline Sources of variation & df & MS & $F$ & $p$ & $F$ vs. & Interpretation and implication for MCA \\
\hline $\mathrm{T}($ after $) \times \mathrm{S}(\mathrm{I}(\mathrm{M}))$ & 12 & & 2.7366 & $>0.05$ & $\begin{array}{l}\text { T(before) } \times \\
\text { S }(\mathrm{I}(\mathrm{M})) \\
\text { two-tailed }\end{array}$ & $\begin{array}{l}\text { Short-term temporal variation among } \\
\text { MCA sites after declaration is not } \\
\text { different from short-term variation } \\
\text { among MCA sites before declaration }\end{array}$ \\
\hline $\mathrm{T}(\mathrm{B}) \times \mathrm{S}(\mathrm{I}(\mathrm{G}(\mathrm{C})))$ & 72 & & & & & \\
\hline $\mathrm{T}($ before $) \times \mathrm{S}(\mathrm{I}(\mathrm{G}(\mathrm{C})))$ & 36 & 0.2438 & & & & \\
\hline Residual & 960 & 0.3788 & & & & \\
\hline Total & 1156 & & & & & \\
\hline
\end{tabular}

Note: B, before vs. after; T, times; G, group; I, island; S, site; M, MCA; C, control; df, degrees of freedom; MS, mean square; Red., redundant term because of significant higher-order interaction; no test, no denominator mean square for creating $F$ test; Cochran's $C=0.1357, p<0.01$.

ally did (i.e., a type II error) (Mapstone 1995). Post hoc Student-Newman-Keuls (SNK) tests were used to differentiate means where significant factors had $>2$ means.

\section{Estimating changes in size using beyond-BACI}

Target species observed within transects were measured with a flexible tape. Individuals observed just outside transects were also measured to increase sample sizes at each site. Trochus were measured across the widest point of the base of the shell. Holothurians were measured in situ, without disturbance, along the top of the body, from mouth to anus, using a tape measure. Clams were measured across the top of the shell as it was not possible to measure shell width because many individuals were embedded in coral.

Too few measurements were made for all taxa to enable a sensible comparison across all temporal and spatial scales, and hence data were pooled across spatial and (or) temporal scales to increase replication. Balanced replication (Underwood 1997) was achieved by randomly discarding data where necessary. Two analyses were used, depending on the number of animals available after pooling. For analysis 1, data were pooled at the group level in the MCA and across all groups within the controls. Data were also pooled across all three times sampled before and three times sampled after declaration of the MCA. A two-factor ANOVA compared (i) the MCA with controls and (ii) before and after declaration of the MCA. Both factors were fixed and orthogonal. Analysis 2 was an asymmetrical ANOVA used to compare sizes of Tridacna maxima. Data were pooled across sites and islands within each of the MCA and control groups. The factors analysed were before vs. after (fixed), times (nested in before vs. after and random), and groups (random), including an asymmetrical comparison of the MCA with the control groups.

\section{Analysis of delta values for abundance and size}

Delta values were calculated for each time before and after declaration of the MCA for data on abundance and size (cf. Osenberg et al. 1994). Here, the deltas were calculated as proportional differences using log-transformed data as

$$
\Delta_{\mathrm{B}}=\mathrm{MCA}_{\mathrm{B}} / \mathrm{CA}_{\mathrm{B}}
$$

and

$$
\Delta_{\mathrm{A}}=\mathrm{MCA}_{\mathrm{A}} / \mathrm{CA}_{\mathrm{A}}
$$

where $\Delta_{\mathrm{B}}$ and $\Delta_{\mathrm{A}}$ are the deltas for each time before and after declaration, respectively; $\mathrm{MCA}_{\mathrm{B}}$ and $\mathrm{MCA}_{\mathrm{A}}$ are the average total counts of an invertebrate per site within the MCA at each time before and after declaration; and $\mathrm{CA}_{\mathrm{B}}$ and $\mathrm{CA}_{\mathrm{A}}$ are the average total counts of an invertebrate per site within all control areas at each time before and after declaration. Delta values for size were based on average size across all sites within the MCA or control areas. $\Delta_{\mathrm{B}}$ and $\Delta_{\mathrm{A}}$ were compared using a one-tailed $t$ test $\left(H_{0}: \Delta_{\mathrm{B}} \geq \Delta_{\mathrm{A}} ; H_{\mathrm{a}}: \Delta_{\mathrm{B}}<\Delta_{\mathrm{A}}\right)$ for all invertebrates except Tectus pyramis, where a two-tailed test was used because we could not predict a direction of change for this species. Post hoc analysis of power $(1-\beta)$ was used to determine $(i)$ the number of samples (i.e., times each before and after declaration) required to achieve $1-\beta \geq$ 0.80 , (ii) the power of $t$ tests required to detect a significant reserve effect for a $25 \%$ and $50 \%$ change in the proportional difference between the MCA and the control areas before and after declaration of the MCA, using the observed mean abundance in $\mathrm{CA}_{\mathrm{B}}$, and (iii) the size of the proportional difference required to achieve $1-\beta \geq 0.80$, with $n=3$. The use of $25 \%$ and $50 \%$ changes is consistent with published abundances of several species of invertebrates elsewhere in the tropical Pacific (e.g., Long and Skewes 1997; Preston and Lokani 1990); these changes were also used for evaluating sizes in the absence of available data from elsewhere.

\section{Results}

Twenty-seven species of commercially exploited invertebrates were recorded: seven species of giant clams, two species of pearl oysters, T. niloticus, and 17 species of holothurians. The nonharvested topshell $T$. pyramis, which was common in the shallow habitat, was also counted. Eight species were abundant enough to warrant statistical analysis. Total abundance of holothurians was also analysed for each habitat. Results of beyond-BACI analyses for T. niloticus are detailed to show the partitioning of variation and sequence of tests used, with details for other abundance variables analysed in the same way presented as summaries.

\section{Abundance of invertebrates in the shallow terrace habitat}

\section{Trochus niloticus and Tectus pyramis}

Establishment of the MCA facilitated an increase in the abundance of T. niloticus (Table 1; Fig. 2a). Abundance of T. niloticus increased threefold at the Arnavon Islands from 
before to after establishment, but numbers remained similar at the control groups over the same period (Fig. 2a). No test was available to compare islands (Table 1), but Fig. $2 b$ suggests there was an increase in abundance at both islands within the MCA, whereas abundances remained similar or decreased at all but one of the control islands. Increases in abundance were inconsistent among sites within islands (Table 1) but tended to increase at all sites in the MCA (significantly so at two sites) while generally remaining similar or tending to decrease at most control sites from before to after declaration (Fig. 3).

The abundance of $T$. pyramis, which occurred in the same habitat as T. niloticus, was unchanged within the MCA from before to after its establishment (Table 2). Abundance varied among the 24 control sites, however, where numbers increased significantly at 11 sites, decreased at 2 , and remained unchanged at 11 .

\section{Tridacna maxima}

The MCA had no overall effect on the abundance of T. maxima (Table 2). Abundance, however, increased at seven of the eight sites in the MCA and at 20 control sites (Fig. 4). Because similar variation occurred at the MCA sites and control sites, the increase in abundance cannot be attributed to the MCA, suggesting broad-scale increases in the region.

\section{Holothurians}

The MCA had no detectable effect on the total abundance of holothurians or of Stichopus chloronotus in the shallow habitat (Table 2). This was despite abundances increasing twofold at the Arnavon Islands from before to after establishment of the MCA and numbers remaining similar at the control groups (Fig. 5a). The sensitivity of the test to identify changes at the MCA relative to control groups $(\mathrm{B} \times$ MCA vs. controls interaction) was probably too low ( $\mathrm{df}=$ $1,2)$ to detect the trend suggested graphically. Temporal variation occurred in the abundance of holothurians among sites at the Arnavons after establishment of the MCA, but this variation did not differ statistically from temporal variation before establishment and, hence, could not be attributed to an effect of the MCA.

\section{Abundance of invertebrates in the deep slope habitat}

\section{Total holothurians}

Establishment of the MCA did not cause a significant increase in the number of holothurians in the deeper slope habitat, but it may have prevented declines in abundance that were evident elsewhere in the region. Abundance varied at the MCA relative to the control groups from before to after declaration (Table $2 b$ ). SNK analyses indicated that abundance remained similar at the Arnavon group from before to after declaration but declined on average by one-third at the control groups (Fig. 5b). There was no variation in total abundance at the scale of sites at the Arnavon Islands from before to after establishment, but at the controls, abundance decreased at 11 sites, increased at 1 , and was unchanged at 12 sites. This suggests that the MCA maintained populations but was ineffective at enhancing them.
Fig. 2. Trochus niloticus. Mean abundance ( \pm standard error) among $(a)$ groups $(n=144)$ and $(b)$ islands $(n=72)$ before (shaded bars) and after (open bars) establishment of the Arnavon Marine Conservation Area. An asterisk (*) indicates significant difference (Student-Newman-Keuls test, $P \leq 0.05$ ).

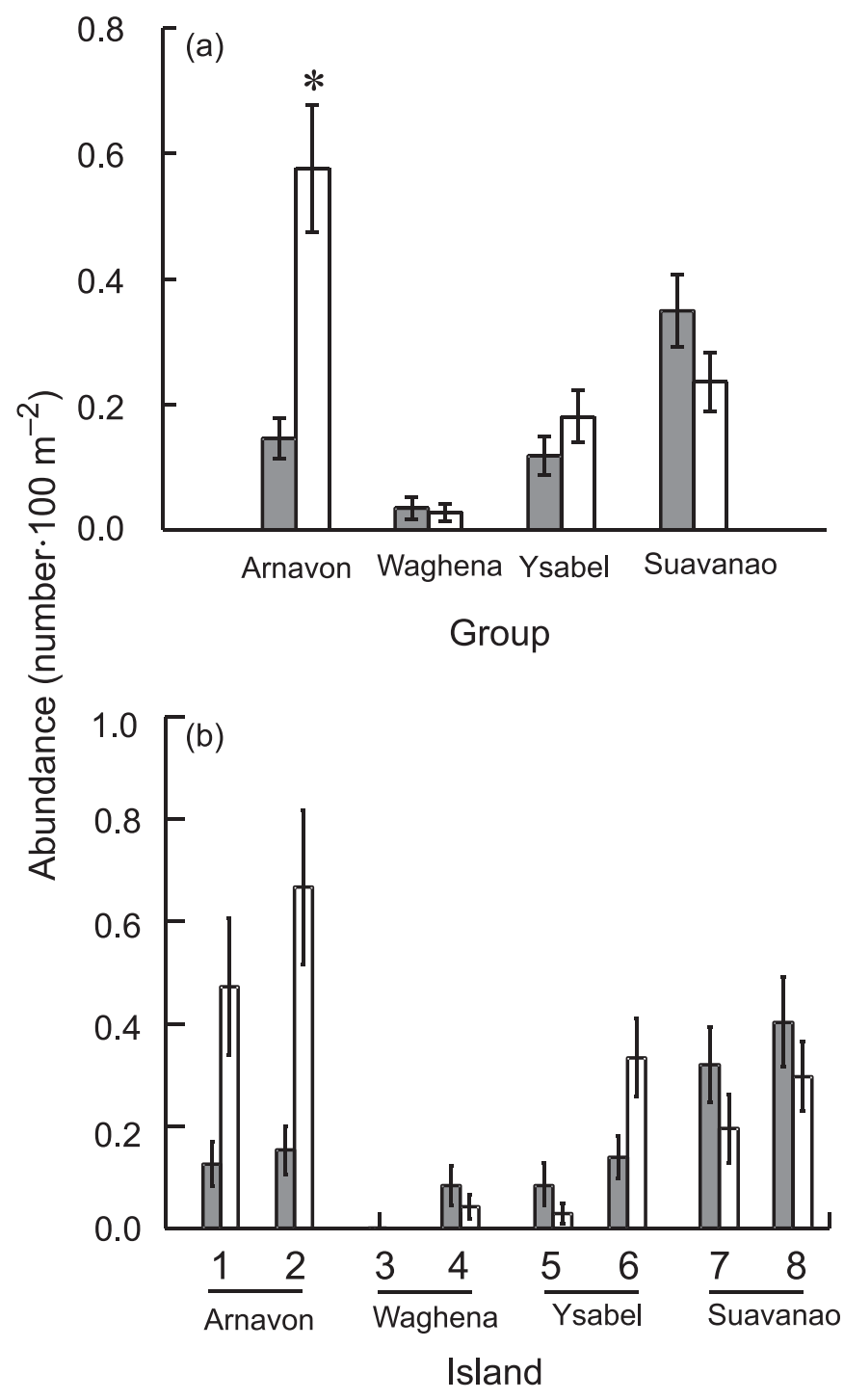

\section{Holothuria fuscogilva}

Establishment of the MCA had a limited effect on numbers of $H$. fuscogilva (Table 2; Fig. 5c). This species differed in abundance between the MCA and control groups from before to after declaration, but SNK tests failed to identify where the differences lay, probably because of the small number of degrees of freedom associated with the tests. Although not detected statistically, abundance almost doubled at the Arnavon group and decreased at the control groups following declaration (Fig. $5 c$ ). At the scale of sites, abundance increased greatly at two sites at the Arnavons and decreased at four sites at the control groups but did not change elsewhere (Fig. 6). Although there were few sites where differences occurred and overall numbers were small, the direction of change suggested that the MCA increased abundance at some sites and prevented declines at others compared with control areas. 
Fig. 3. Trochus niloticus. Mean abundance ( \pm standard error) among sites $(n=18)$ before (shaded bars) and after (open bars) establishment of the marine conservation area: (a) Arnavon Marine Conservation Area; $(b)$ Waghena; $(c)$ Ysabel; and $(d)$ Suavanao. An asterisk (*) indicates significant difference (Student-Newman-Keuls test, $P \leq 0.05$ ).
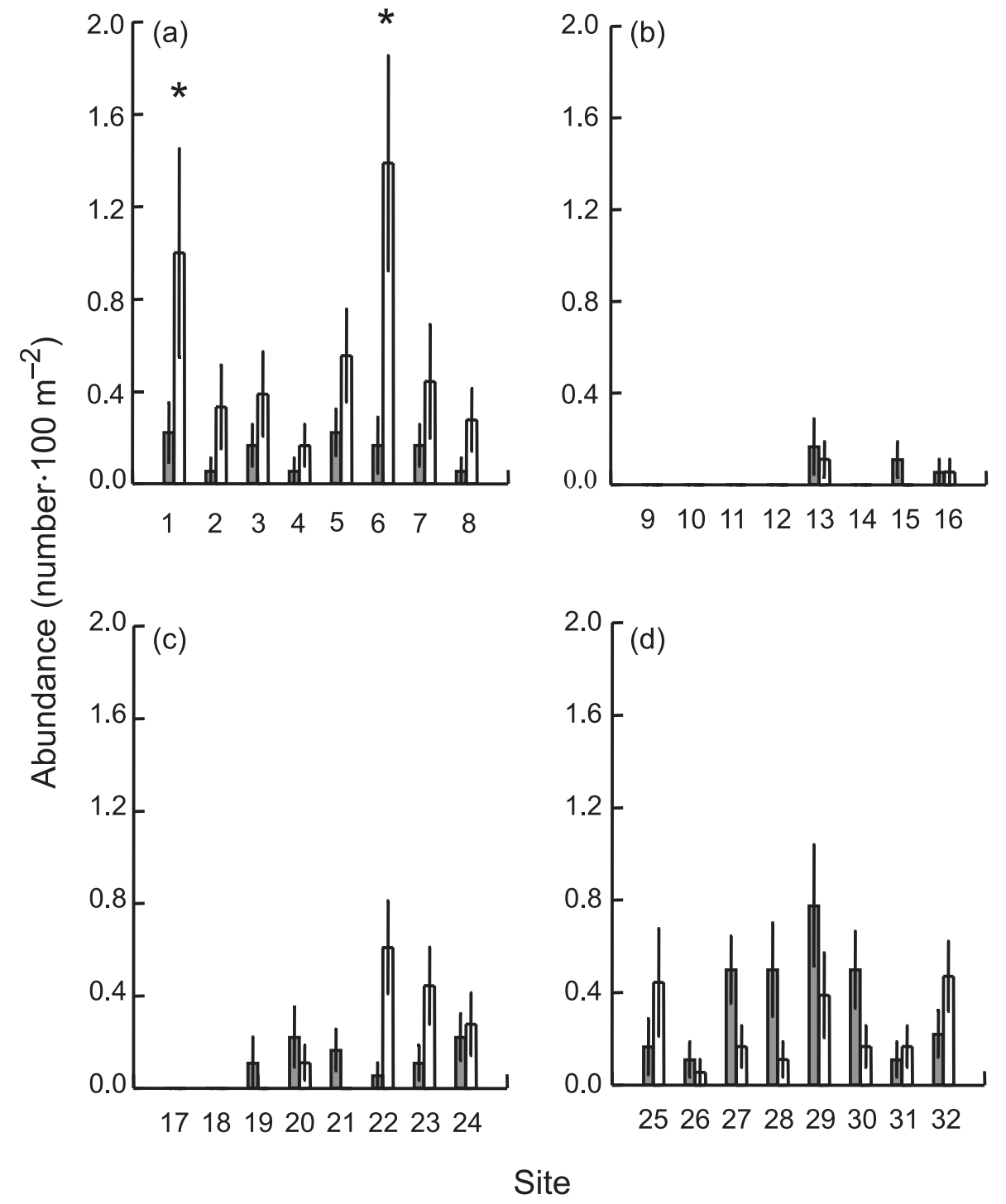

\section{Holothuria atra}

Establishment of the MCA had no measurable effect on the abundance of $H$. atra (Table 2). There were relatively large numbers of $H$. atra at the MCA, but patterns of abundance among groups did not change from before to after declaration. Short-term temporal variation was detected at the MCA after declaration but similar variation also occurred beforehand, indicating that it was not caused by the MCA (Table 2). Similarly, short-term temporal variation occurred among sites within the MCA after declaration. This variation was inconsistent from before to after declaration, but similar differences in temporal variation occurred at controls, thus temporal variation appeared unrelated to the MCA.

\section{Thelanota anax and Holothuria fuscopunctata}

Beyond-BACI indicated that the MCA did not affect abundances of $T$. anax or $H$. fuscopunctata (Table 2). Thelanota anax did not increase at any site in the MCA, but
SNK tests indicated that abundance decreased at 4 of the control sites, remained unchanged at 19 sites, and increased at 1 site. Abundance of $H$. fuscopunctata increased at one site in the MCA after its establishment, but similar variation was recorded among control sites.

\section{Effect of the MCA on sizes of invertebrates}

Using analysis 1 , the mean size of $T$. niloticus varied inconsistently through time (before vs. after $\times$ groups interaction, $F=19.25, p<0.0001$, df $=1,128, n=33)$. Size increased within, and decreased outside, the MCA (Fig. 7a). Moreover, before declaration, T. niloticus tended to be smaller at the Arnavon Islands, but 3 years after declaration, they were significantly larger inside than outside the MCA. We did not observe recruitment of small juveniles during the study, which would tend to reduce mean size. Holothuria fuscogilva also showed a significant interaction between before vs. after and groups $(F=4.919, p=0.028$, df $=1,136$, $n=35$ ), i.e., animals tended to be smaller on average after 
Table 2. Summary of asymmetrical analysis of variance examining temporal and spatial variation in the abundance of selected taxa and derived variables: $(a)$ shallow terrace habitat and $(b)$ deep slope habitat.

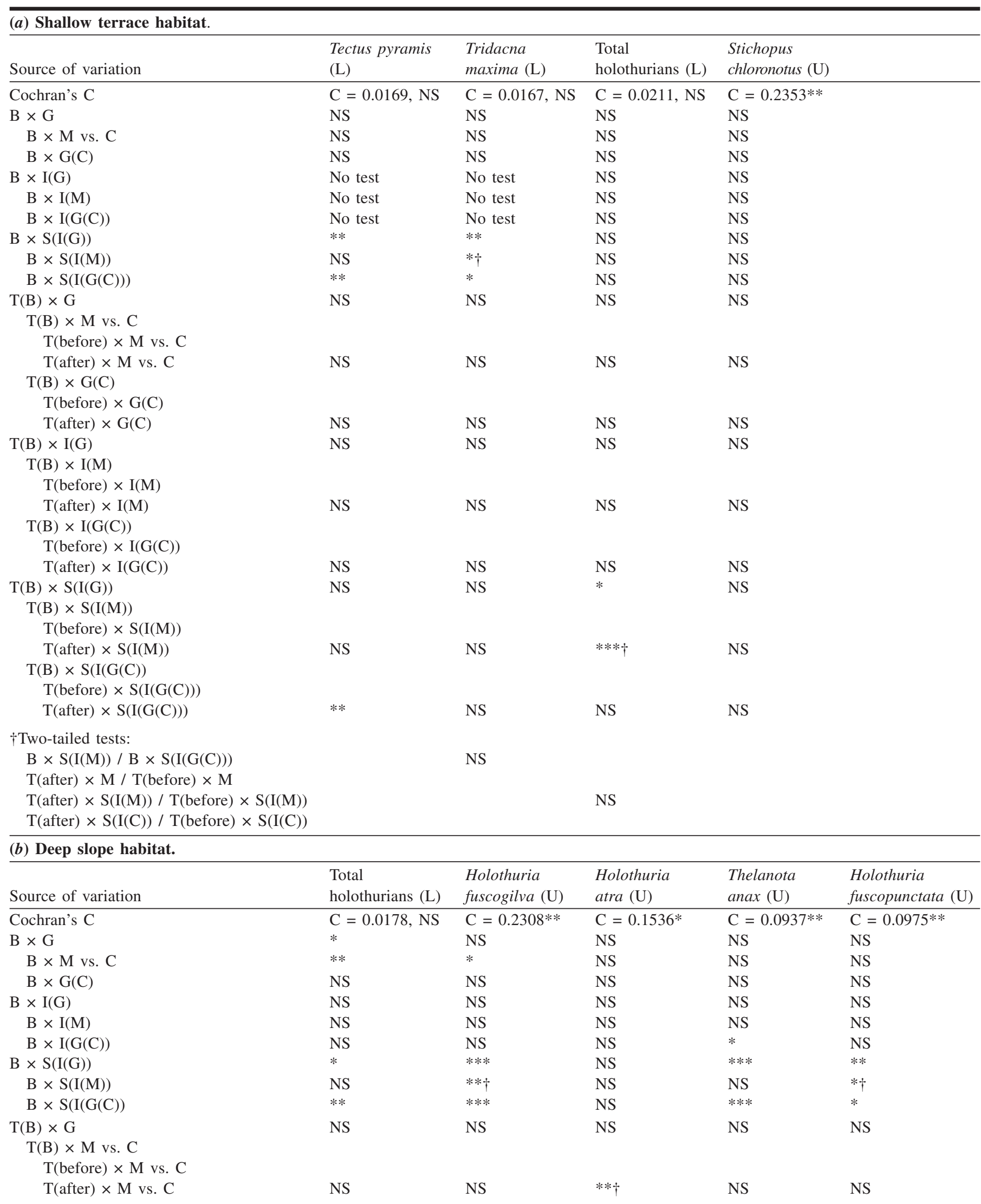


Table 2 (concluded).

\begin{tabular}{|c|c|c|c|c|c|}
\hline Source of variation & $\begin{array}{l}\text { Total } \\
\text { holothurians (L) }\end{array}$ & $\begin{array}{l}\text { Holothuria } \\
\text { fuscogilva (U) }\end{array}$ & $\begin{array}{l}\text { Holothuria } \\
\text { atra }(\mathrm{U})\end{array}$ & $\begin{array}{l}\text { Thelanota } \\
\operatorname{anax}(\mathrm{U})\end{array}$ & $\begin{array}{l}\text { Holothuria } \\
\text { fuscopunctata (U) }\end{array}$ \\
\hline \multicolumn{6}{|l|}{$\mathrm{T}(\mathrm{B}) \times \mathrm{G}(\mathrm{C})$} \\
\hline \multicolumn{6}{|l|}{$\mathrm{T}$ (before) $\times \mathrm{G}(\mathrm{C})$} \\
\hline $\mathrm{T}($ after $) \times \mathrm{G}(\mathrm{C})$ & NS & NS & NS & NS & NS \\
\hline $\mathrm{T}(\mathrm{B}) \times \mathrm{I}(\mathrm{G})$ & NS & NS & NS & NS & NS \\
\hline \multicolumn{6}{|l|}{$\mathrm{T}(\mathrm{B}) \times \mathrm{I}(\mathrm{M})$} \\
\hline \multicolumn{6}{|l|}{$\mathrm{T}(\mathrm{B}) \times \mathrm{I}(\mathrm{G}(\mathrm{C}))$} \\
\hline \multicolumn{6}{|l|}{$\mathrm{T}$ (before) $\times \mathrm{I}(\mathrm{G}(\mathrm{C}))$} \\
\hline $\mathrm{T}($ after $) \times \mathrm{I}(\mathrm{G}(\mathrm{C}))$ & NS & NS & NS & NS & NS \\
\hline $\mathrm{T}(\mathrm{B}) \times \mathrm{S}(\mathrm{I}(\mathrm{G}))$ & NS & NS & NS & NS & NS \\
\hline \multicolumn{6}{|l|}{$\mathrm{T}(\mathrm{B}) \times \mathrm{S}(\mathrm{I}(\mathrm{M}))$} \\
\hline \multicolumn{6}{|l|}{$\mathrm{T}($ before $) \times \mathrm{S}(\mathrm{I}(\mathrm{M}))$} \\
\hline \multicolumn{6}{|l|}{$†$ †wo-tailed tests: } \\
\hline $\mathrm{B} \times \mathrm{S}(\mathrm{I}(\mathrm{M})) / \mathrm{B} \times \mathrm{S}(\mathrm{I}(\mathrm{G}(\mathrm{C})))$ & & NS & & & NS \\
\hline $\mathrm{T}($ after $) \times \mathrm{M} / \mathrm{T}$ (before $) \times \mathrm{M}$ & & & NS & & \\
\hline $\mathrm{T}($ after $) \times \mathrm{S}(\mathrm{I}(\mathrm{M})) / \mathrm{T}($ before $) \times \mathrm{S}(\mathrm{I}(\mathrm{M}))$ & & & $* *$ & & \\
\hline $\mathrm{T}($ after $) \times \mathrm{S}(\mathrm{I}(\mathrm{C})) / \mathrm{T}($ before $) \times \mathrm{S}(\mathrm{I}(\mathrm{C}))$ & & NS & $* *$ & & \\
\hline
\end{tabular}

Note: Only terms relevant to determining whether the Arnavon Islands Marine Conservation Area (MCA) has been effective have been presented. See Table 1 for full design. B, before vs. after; T, times; G, group; I, island; S, site; NS, nonsignificant; *, $p<0.05$; **, $p<0.01 ; * * *, p<0.001$; $\mathrm{U}$, untransformed data used; L, data $\ln (x+1)$ transformed. $\dagger$ indicates that a subsequent two-tailed test was required.

declaration of the MCA at the Arnavons, but larger at the controls (Fig. $7 b$ ). In the period after declaration, mean size inside the MCA was significantly less than mean size outside. We did observe some smaller $H$. fuscogilva in the MCA after declaration. These individuals were $\sim 30 \mathrm{~cm}$ and are unlikely to represent a recent settlement of small juveniles. Two other species examined using analysis 1 showed no variation consistent with a reserve effect. Holothuria atra ( $n=69)$ and $H$. fuscopunctata $(n=40)$ both showed differences in size between the MCA and controls that did not differ through time. Holothuria atra were significantly smaller in the MCA $($ mean $=44.35 \mathrm{~cm} \pm 0.52 \mathrm{~cm}$ standard error) than outside $(46.34 \mathrm{~cm} \pm 0.49 \mathrm{~cm})$, whereas the reverse occurred for $H$. fuscopunctata (MCA, $48.30 \mathrm{~cm} \pm 0.62 \mathrm{~cm}$; controls, $46.53 \mathrm{~cm} \pm 0.53 \mathrm{~cm})$.

Using analysis 2 , the mean size of $T$. maxima showed no effect consistent with declaration of the MCA (Table $3 a$ ). This was indicated by nonsignificant tests for the asymmetrical components of the analysis. Rather, there was variation among times before declaration that was consistent among groups and significant variation among groups that was consistent through time (Table $3 b$ ).

\section{Analysis of delta values and calculation of power}

The analysis of delta values was generally consistent with the beyond-BACI analyses at the largest spatial scale of the MCA vs. control areas (Table 4). An exception was the abundance of $T$. anax, which indicated more individuals within the MCA relative to the control areas from before to after declaration. The ratios of observed proportional differences between MCA and control areas from before to after declaration were generally quite small, suggesting a relatively small effect after 3 years of closure in the MCA. Post hoc power analysis for nonsignificant variables indicated that a large number of sampling times would have been required to have a good chance of detecting the observed ratios, and that estimates of power were variable among species (e.g., ranging from 0.262 for a $50 \%$ change in Stichopus chloronotus to 1 for a $25 \%$ change in T. maxima). Notwithstanding this, the study would have had a reasonable power to detect an even smaller effect for T. niloticus (abundance and size) and, in the deep habitat, for abundances of total holothurians, H. fuscogilva, and T. anax. Although power analyses were used to examine an increase in abundance and (or) size in most species, power was determined for a potential decrease in abundance of $T$. pyramis in the MCA relative to the controls based on the results of the beyond-BACI analysis. Here there would have been a large power to detect a $50 \%$ decrease in abundance of $T$. pyramis within the MCA compared with the controls.

\section{Discussion}

\section{Effect of MCA on abundance}

Commercially harvested marine invertebrates showed a range of responses to establishment of the MCA at the Arnavon Islands, which were evident using beyond-BACI and the comparison of delta values. Overall, the delta values simplified the interpretation of patterns in favour of either no effect or an increase in relative abundance in the MCA. The most notable response was that abundances of some of the most valuable and heavily exploited species (T. niloticus and 
Fig. 4. Tridacna maxima. Mean abundances ( \pm standard error) among sites before (shaded bars) and after (open bars) establishment of the marine conservation area $(n=18)$ : $(a)$ Arnavon Marine Conservation Area; $(b)$ Waghena; $(c)$ Ysabel; and $(d)$ Suavanao. An asterisk (*) indicates significant difference (Student-Newman-Keuls test, $P \leq 0.05$ ).
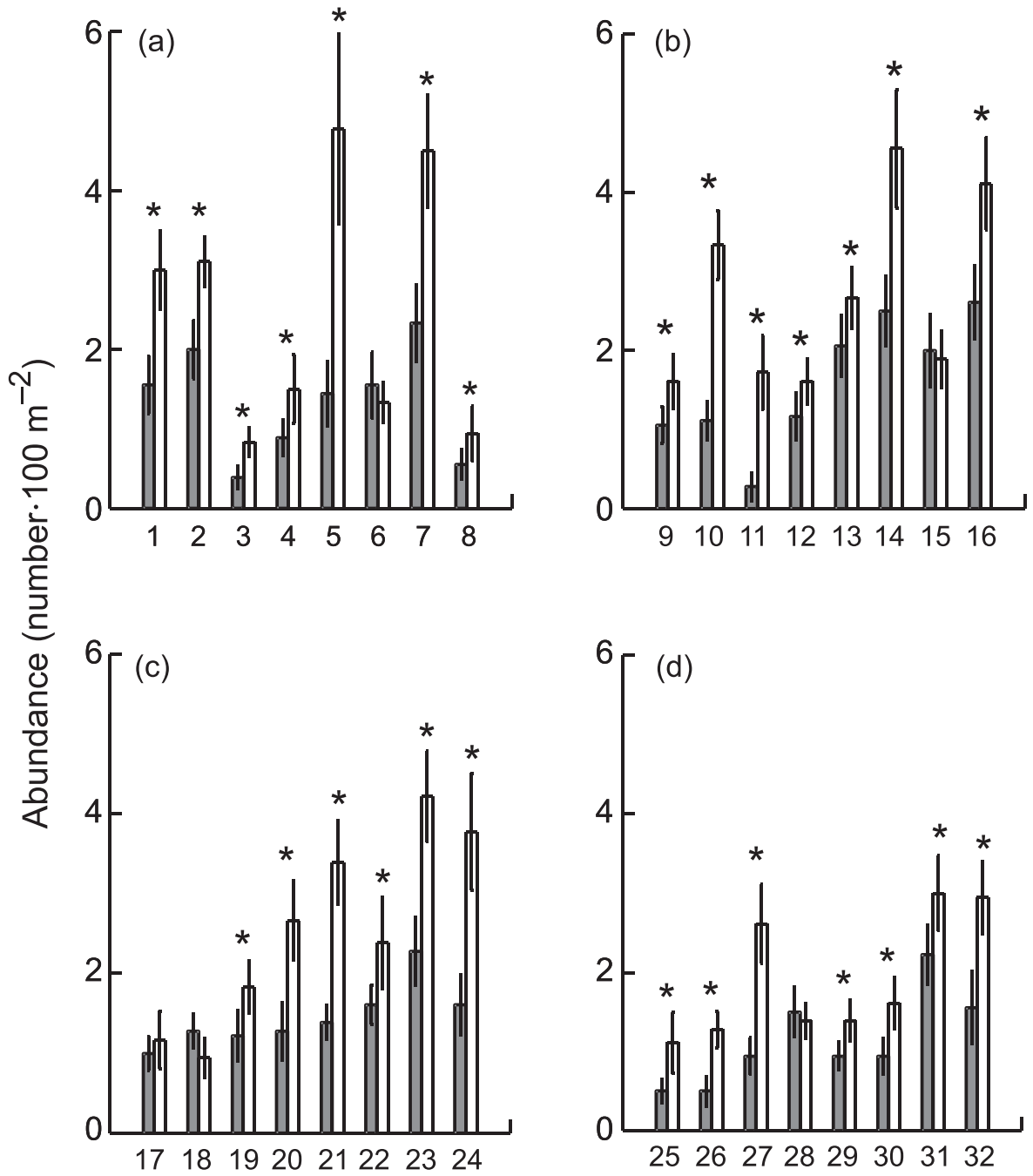

Site

H. fuscogilva) increased in the MCA relative to fished (control) areas. The increase in abundance of $T$. niloticus was most evident at two of the eight sites at the Arnavon Islands. This small-scale variation may be due to (unknown) attributes of the habitat at different sites, variation in recruitment to an observable size, or stochastic processes. Alternatively, there were some reported instances of poaching within the MCA, which may have occurred more frequently at some sites than others, negating the potential benefits of protection. Thus, if social or logistical factors make it difficult to establish large areas for protection of trochus, effective replenishment of stocks may be possible within multiple smaller areas.

The MCA had one of three effects for other species. First, while numbers did not increase in the MCA, the reserve appeared to prevent declines in abundance apparent elsewhere in the region: total holothurians and T. anax in the deep habitat were in this category. Analysis of delta values did not identify this effect because the ratio estimator could have changed because of either an increase in the MCA or a decrease elsewhere. We cannot exclude the possibility that the MCA caused a redistribution of harvesting effort to areas outside the MCA, including controls (Halpern et al. 2004). Such an effect may accelerate declines, overemphasizing the benefits of the reserve. We do not consider this to be the case here, however, because the controls were distributed over a large area and the habitats studied were common throughout the general area, but the possibility does stress the need to understand how fishing effort may change after declaration of marine reserves.

Second, the MCA had no effect on abundance for five variables: Stichopus chloronotus, abundance of holothurians in the shallow habitat, T. maxima, $H$. atra, and $H$. fuscopunctata.

Third, T. pyramis, the only nonharvested species studied, appeared to increase at almost half the control sites, but at 
Fig. 5. Mean abundances ( \pm standard error) of $(a)$ total holothurians in shallow habitat, $(b)$ total holothurians in deep habitat, and (c) Holothuria fuscogilva in the deep habitat among groups before (shaded bars) and after (open bars) establishment of the Arnavon Marine Conservation Area $(n=144)$.
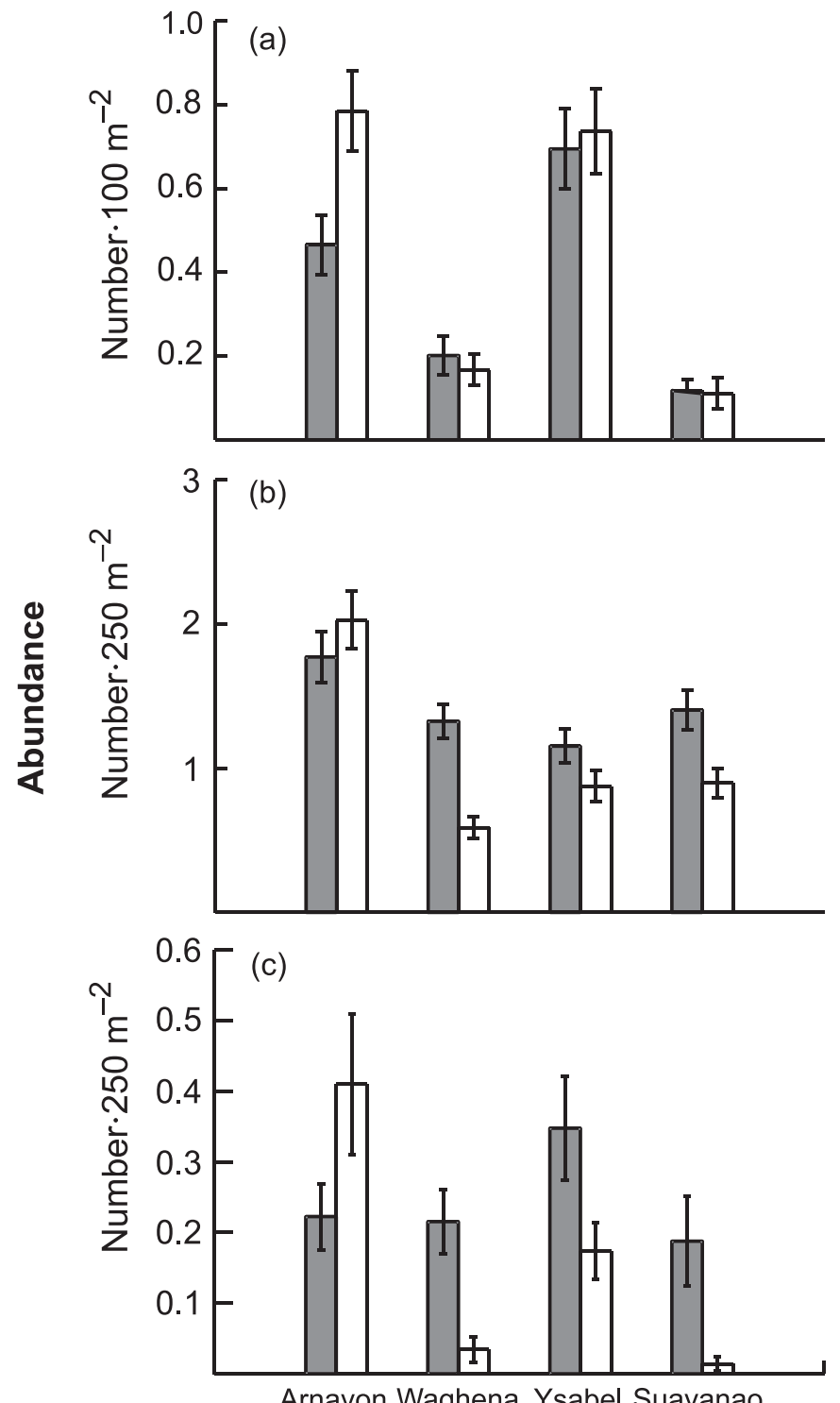

Group

none of the Arnavon sites, suggesting that the MCA may have inhibited an increase in abundance there. One explanation for this pattern may be that T. niloticus, which increased in the MCA, limited abundance of $T$. pyramis through competition while depletion of $T$. niloticus at the control areas alleviated competition and allowed abundances of T. pyramis to increase. Both species graze on algae, grow to similar sizes, and occupy similar habitats on the reef terrace. Competition between these species remains to be demonstrated, but our results indicate that establishment of reserves to manage exploited species may have indirect effects on nontarget species. Effects on nontarget species occurring in marine reserves have not been examined widely but may occur because of changes in relative abundance of harvested and nonharvested species (e.g., Andrew and MacDiarmid 1991; McClanahan and Arthur 2001).

The lack of increases in abundance within the MCA for several species may mean that marine reserves are inappropriate for managing those species or that longer periods of time are needed for recovery, particularly for holothurians (Uthicke et al. 2004). Meagre spawning success, patchy distributions of larvae, and the size and location of the MCA may interact to reduce the probability of substantial settlement of species with pelagic larval phases. The cryptic nature of juvenile holothurians, which often have diel burrowing cycles and occur in different habitats to the adults (Reichenbach 1999; Mercier et al. 2000), would also reduce the likelihood of detecting a relatively rapid increase in abundance following protection from fishing if juvenile holothurians remained cryptic for several years.

The corollary to limited settlement is that $T$. niloticus and H. fuscogilva, which increased in the MCA, were present as cryptic juveniles before declaration or settled during the closure and then grew to a size where they could be seen during the "after" surveys. The smallest holothurians sampled were $100 \mathrm{~mm}$ long. Although growth varies among species of holothurians, some species have estimated growth rates of 0.5-1.7 $\mathrm{cm} \cdot \mathrm{month}^{-1}$ (Shelley 1985; Conand 1986) or 35$533 \mathrm{~g} \cdot \mathrm{year}^{-1}$ (Uthicke et al. 2004). This suggests that 3 years was sufficient time for newly recruited holothurians to grow to a size where they would be recorded by divers. Similarly, T. niloticus can grow to $\sim 8 \mathrm{~cm}$ within 3 years (Nash 1993). The smallest $T$. niloticus we sampled were $\sim 6 \mathrm{~cm}$, again suggesting that 3 years was sufficient for recruits that settled at the time of establishment of the MCA to be sighted, though those that settled subsequently may not have been counted.

The time needed for a species to recover from harvesting will depend on factors such as generation time, severity and extent of previous fishing, local oceanographic features, location and size of the reserve, infringement of the reserve, and availability of nursery and adult habitat. Our study suggests that it may take many years to restore each of the target species to preharvest levels, assuming the reserve is an effective mechanism for mediating fishing. In the absence of data on the size of any local remnant unfished populations, comparison of data from the MCA with areas elsewhere in the western Pacific indicates that abundance of T. niloticus and $H$. fuscogilva in the MCA were still at the lower end of densities in the region. Three years after closure, densities of $H$. fuscogilva were estimated at 16 individuals $\cdot \mathrm{ha}^{-1}$, which was comparable with density estimates for unfished reefs in the eastern Torres Strait (7-30 individuals $\cdot \mathrm{ha}^{-1}$; Long and Skewes 1997) but well below maximum estimates of 82 individuals $\cdot \mathrm{ha}^{-1}$ in Tonga (Preston and Lokani 1990). Uthicke et al. (2004) also suggested that recovery by Holothuria nobilis from harvesting could require decades. Although abundance of $T$. niloticus increased to 57 individuals $\cdot \mathrm{ha}^{-1}$ in the MCA, this was also below estimates of densities from other areas (62-2016 individuals $\cdot \mathrm{ha}^{-1}$; Long et al. 1993; Nash et al. 1995). Further monitoring is needed to determine if longer closures can lead to densities similar to those found elsewhere in the region. Importantly, the power analyses suggest that the study would have had a good chance of de- 
Fig. 6. Holothuria fuscogilva. Mean abundance ( \pm standard error) among sites $(n=18)$ before (shaded bars) and after (open bars) establishment of the marine conservation area: $(a)$ the Arnavon Marine Conservation Area; $(b)$ Waghena; $(c)$ Ysabel; and $(d)$ Suavanao. An asterisk (*) indicates significant difference (Student-Newman-Keuls test, $P \leq 0.05$ ).

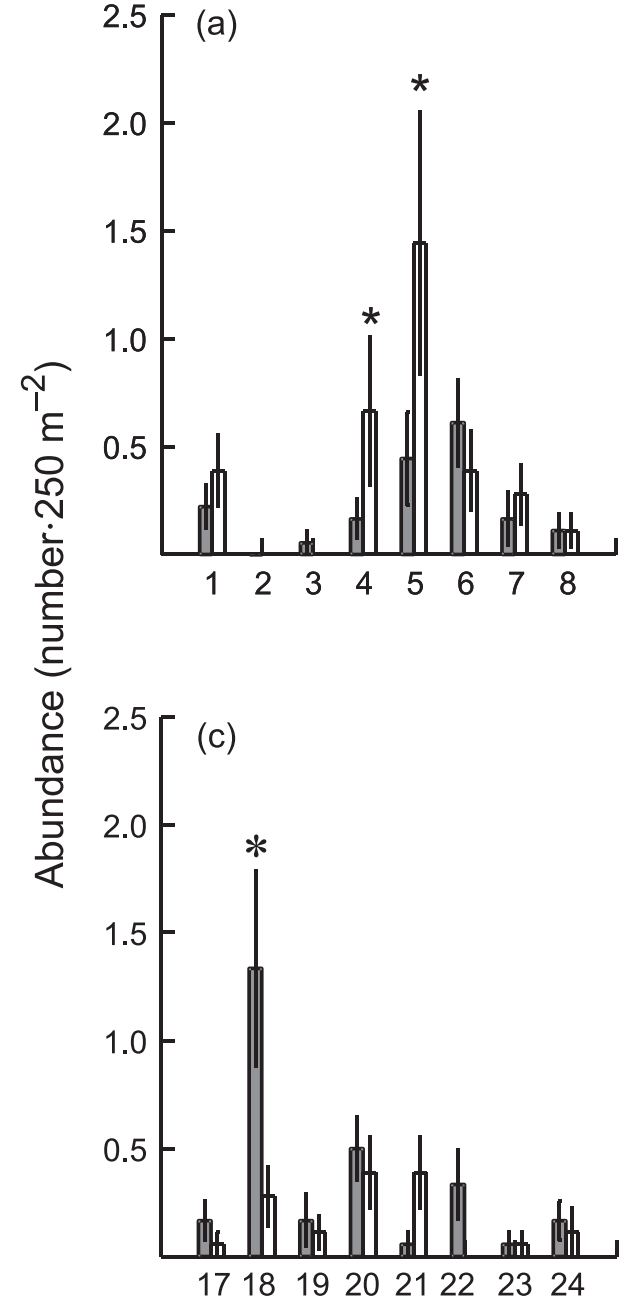

tecting effect sizes comparable with the densities of invertebrates recorded by others.

\section{Effect of MCA on body size of species}

The full beyond-BACI design could not be utilized for data on sizes because of limited numbers of individuals available for measurement. Using the reduced designs and the delta values, two of five species showed a change in size consistent with establishment of the reserve. The increase in size of $T$. niloticus meant that, on average, this species exceeded its upper legal size limit $(11 \mathrm{~cm})$ and hence had even greater protection because of difficulties in selling large individuals. Conversely, individuals outside the MCA were still within the legal size range but were significantly smaller after 3 years than previously. Thus, overharvesting could ultimately lead to $T$. niloticus outside the MCA being too small to harvest legally, and those within the MCA becoming too large.

The mean size of $H$. fuscogilva increased at the controls after establishment of the MCA, probably because of growth
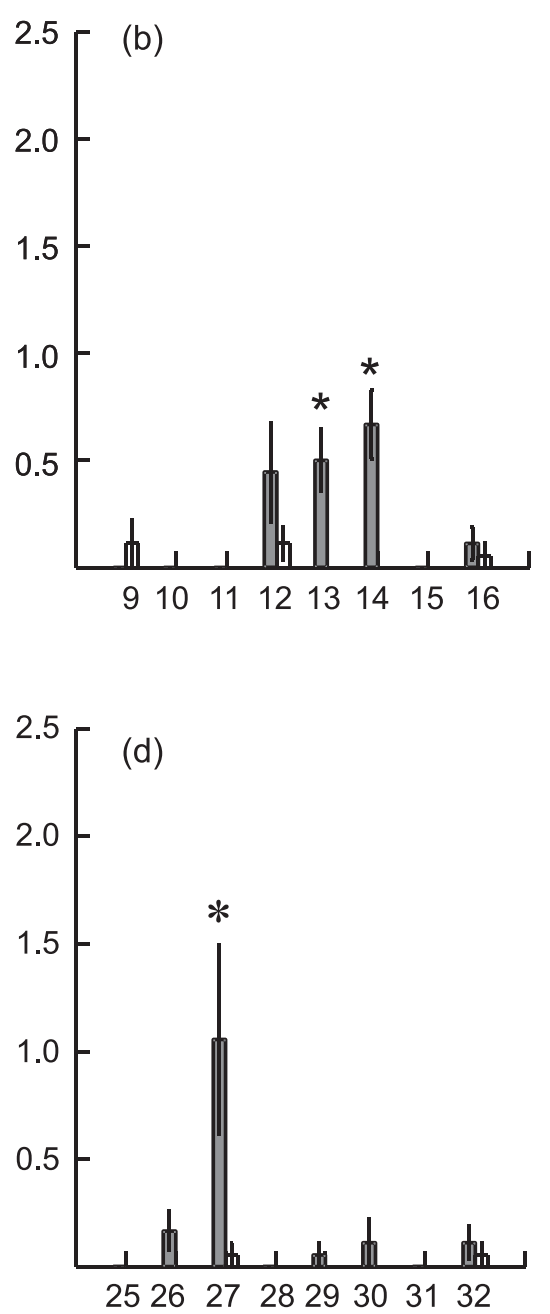

Site

of smaller animals and an apparent lack of recruitment into smaller size classes. Some recruitment of smaller size classes was observed at the Arnavons, suggesting a small (but nonsignificant) decrease in the mean size of animals. Thus, the size distributions of animals may later change in various ways following protection from harvesting. This effect was not detected by analysis of delta values because our original hypothesis was that there would be an increase in size within the MCA. Our data suggest that responses in the size of harvested invertebrates to establishment of the MCA can be expected to be complex, especially where the fisheries are regulated by minimum and maximum size limits.

\section{Advantages and disadvantages of the experimental design}

This study has shown that it is possible to design sampling programmes to detect a reserve effect but that the interpretation of results is more complex than assessment of what happens within a reserve - changes must be considered in a regional context. Although the simpler approach to analyzing delta values has appeal at the broader scale of 
Fig. 7. Mean size ( \pm standard error) of (a) Trochus niloticus $(n=$ 33 ) and (b) Holothuria fuscogilva $(n=35)$ at the Arnavon group and control groups (pooled) before (shaded bars) and after (open bars) establishment of the Arnavon Marine Conservation Area. Significant differences between means (Student-Newman-Keuls tests): *, $P \leq 0.05$; **, $P \leq 0.01$.

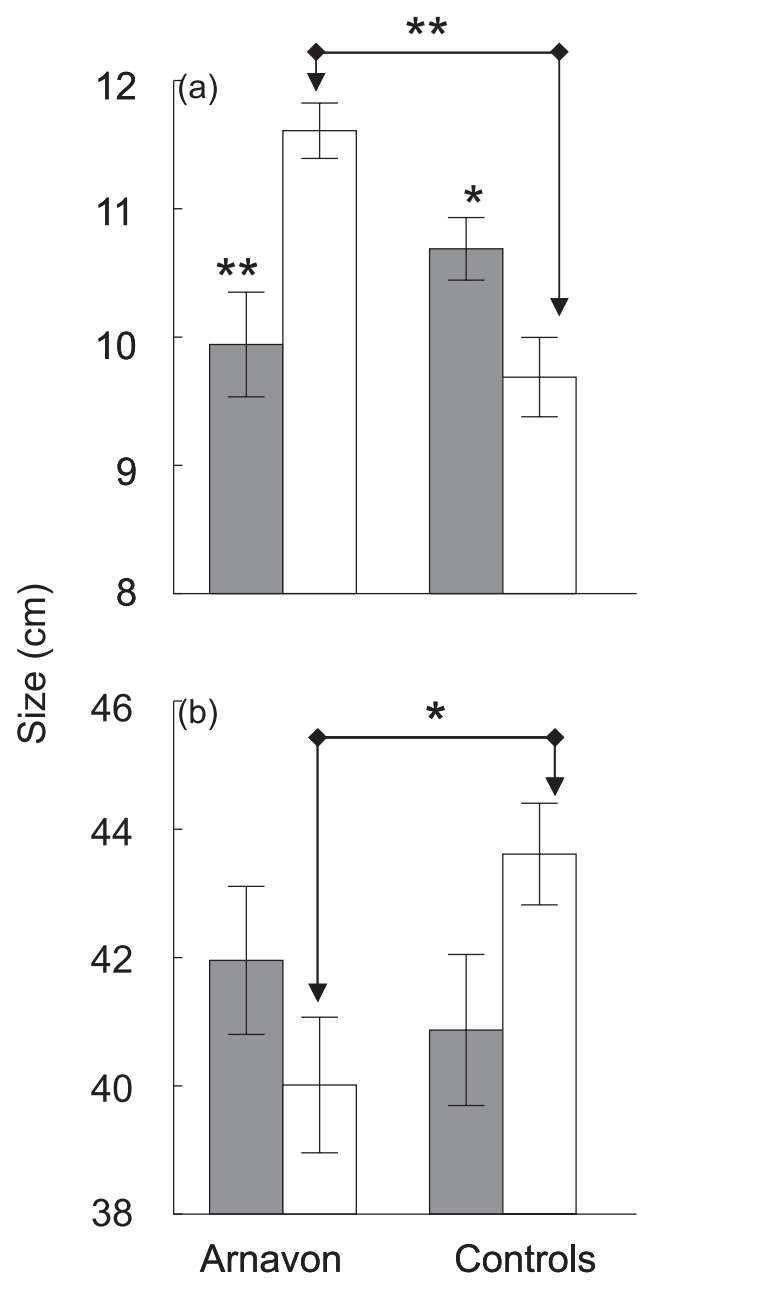

Group

comparing a marine reserve with controls, it has limited value for interpretation and management, although it can provide a good indication of statistical power and effect sizes at the larger scale. Other critical factors affecting the sampling design and interpretation of data include the reason for the declaration of the reserve, duration of the sampling programme, and number of reserves and sites within reserves available for sampling. Our study illustrates this in three ways. First, the experimental design we used was based on the proposition that the term "groups" is a random factor (Eberhardt 1976; Stewart-Oaten and Bence 2001) with respect to the performance indicators selected. This implies that the beyond-BACI design is valid for marine reserves selected according to factors independent of the indicators. In some cases, however, reserves are selected for specific biological attributes, such as the presence of a spawning ground, particularly high biodiversity, etc. Therefore, there will be cases in which selection of a reserve would not be random with respect to performance indicators and an alternative approach is required (see also Willis et al. 2003).

Second, the temporal component of the design entailed three sampling times (spanning $<1$ year), each before and after declaration of the MCA, with 3 years between. It is unlikely that this relatively short time would be sufficient to establish a time series of change in abundance or size, but the study timing was constrained by external factors, including enlisting local co-operation and acceptance of the closure at the Arnavon Islands and, ultimately, poaching within the MCA resulting from civil strife within Solomon Islands between 1999 and 2002. The former types of constraints are likely to be a feature of the management of many marine reserves. This design, however, provides three replicated estimates of abundance and animal size, which enhances our confidence in the relationship between the Arnavon Islands and the control groups before and after declaration of the MCA. This can be critical where variable environmental conditions (water clarity, sea conditions, etc.) can bias counts among times and where population changes may occur over a short time scale (e.g., recruitment events). Therefore, although it may be desirable to establish a longer time series before declaration (cf. Stewart-Oaten and Bence 2001), there is merit in obtaining samples over shorter time periods, if time is limited.

Finally, the use of asymmetrical ANOVA provided a comprehensive method for testing the effectiveness of the MCA. Even so, the tests sometimes failed to verify strong apparent trends, particularly when the sensitivity of a test within the analytical model was likely to be low. Determining power for terms of interest in complicated asymmetrical designs is difficult, although this issue has been considered for impact studies by modelling with simulated data (Underwood and Chapman 2003). In our study, the calculation of power on the simplified design using delta values gave important insight into effect sizes at the MCA-control scale and may be a useful initial step for management. More broadly, lack of power can be addressed in several ways: $(i)$ by increasing spatial replication, $(i i)$ by incorporating multiple marine reserves (e.g., Russ 2002), and (iii) by including additional periods of sampling. Firstly, in our study, replication could have been increased within sites (i.e., the number of transects) or by increasing the number of sites and (or) control groups. Secondly, if practical, it would be preferable to sample two or more separate marine reserves within one design. This enhances the generality of results and enables the use of different types of design, with replication of both control and reserve treatments. This type of approach may not be possible in many areas for social and logistical reasons but would be useful in large managed areas, such as the Great Barrier Reef, Australia (Campbell et al. 2001). Thirdly, the same design could be used to compare data from the "before" period with three times the sampling taken, say, 6 years "after" declaration. Presumably, if the MCA is successfully enhancing the abundances and sizes of invertebrates, then the effect size will increase (to a limit) over time.

Wherever marine reserves are declared to help sustain fisheries, the key issue for assessing the effectiveness of the reserve for target species is to ensure that the data are ob- 
Table 3. Analyses examining the effect of the establishment of the Arnavon Islands Marine Conservation Area on the size of Tridacna maxima $(n=47)$ : $(a)$ asymmetrical analysis of variance and $(b)$ Student-Newman-Keuls results for significant terms.

\begin{tabular}{|c|c|c|c|c|c|c|}
\hline \multicolumn{2}{|l|}{ Sources of variation } & df & MS & $F$ & $P$ & F vs. \\
\hline \multicolumn{2}{|l|}{$\mathrm{B}$} & 1 & 343.4235 & 0.8327 & 0.4131 & $\mathrm{~T}(\mathrm{~B})$ \\
\hline \multicolumn{2}{|l|}{ G } & 3 & 1039.2307 & 22.7069 & $<0.0001$ & $\mathrm{~T}(\mathrm{~B}) \times \mathrm{G}$ \\
\hline \multicolumn{2}{|l|}{ BG } & 3 & 11.0435 & 0.2413 & 0.8675 & Residual \\
\hline \multicolumn{2}{|l|}{$\mathrm{B} \times \mathrm{M}$ vs. $\mathrm{C}$} & 1 & 0.9941 & 0.0217 & 0.8829 & Residual \\
\hline \multicolumn{2}{|l|}{$\mathrm{T}(\mathrm{B}) \times \mathrm{M}$ vs. $\mathrm{C}$} & 4 & 94.4862 & & & \\
\hline \multicolumn{2}{|l|}{$\mathrm{T}$ (before) $\times \mathrm{M}$ vs. $\mathrm{C}$} & 2 & 187.5333 & & & \\
\hline \multicolumn{2}{|l|}{$\mathrm{T}($ after $) \times \mathrm{M}$ vs. $\mathrm{C}$} & 2 & 1.4390 & 0.0314 & 0.9690 & Residual \\
\hline \multicolumn{2}{|l|}{$\mathrm{T}(\mathrm{B}) \times$ among $\mathrm{C}$} & 8 & 63.2746 & & & \\
\hline \multicolumn{2}{|l|}{$\mathrm{T}$ (before) $\times$ among $\mathrm{C}$} & 4 & 112.6054 & & & \\
\hline \multicolumn{7}{|c|}{$\begin{array}{ll}\text { Sources of variation } & \text { Treatment means }\end{array}$} \\
\hline $\mathrm{T}(\mathrm{B})$ : before & \multicolumn{6}{|c|}{$\mathrm{T} 1(22.89 \pm 0.54)>\mathrm{T} 2(20.58 \pm 0.47)=\mathrm{T} 3(19.31 \pm 0.54)$} \\
\hline $\mathrm{T}(\mathrm{B}):$ after & \multicolumn{6}{|c|}{$\mathrm{T} 4(18.63 \pm 0.50)=\mathrm{T} 5(20.34 \pm 0.52)=\mathrm{T} 6(20.51 \pm 0.48)$} \\
\hline \multirow[t]{2}{*}{ Groups } & Waghena & $=$ Suavanao & $=$ Ysabel & $<$ Arnavons & & \\
\hline & $18.30 \pm 0.40$ & $20.07 \pm 0.42$ & $20.19 \pm 0.40$ & $22.95 \pm 0.42$ & & \\
\hline
\end{tabular}

\footnotetext{
Note: B, before vs. after; T, times; G, groups; $\mathrm{C}$, controls; Cochran's $\mathrm{C}=0.0568, P<0.05$. In $(b)$, the numbers in parentheses represent the mean \pm standard error.
}

Table 4. $t$ tests and power analyses comparing the abundance or size (where indicated) of invertebrates in the Arnavon Islands Marine Conservation Area (MCA) with those in the control areas (CA) before and after declaration of the MCA.

\begin{tabular}{|c|c|c|c|c|c|c|}
\hline Variable & $\begin{array}{l}\text { Probability } \\
(t \text { test })\end{array}$ & $\begin{array}{l}\text { Observed } \\
\text { ratio }^{a}\end{array}$ & $\begin{array}{l}n \text { for } \\
1-\beta \geq 0.80\end{array}$ & $\begin{array}{l}1-\beta \\
(25 \% \text { change })\end{array}$ & $\begin{array}{l}1-\beta \\
(50 \% \text { change })\end{array}$ & $\begin{array}{l}\text { Ratio for } \\
1-\beta \geq 0.80^{b}\end{array}$ \\
\hline \multicolumn{7}{|l|}{ Shallow habitat } \\
\hline Trochus niloticus & 0.009 & 2.67 & - & - & - & 2.10 \\
\hline T. niloticus size & 0.018 & 1.25 & - & - & - & 1.20 \\
\hline Tectus pyramis ${ }^{c}$ & 0.254 & 0.85 & 10 & 0.643 & 0.989 & 0.65 \\
\hline Tridacna maxima & 0.129 & 1.03 & 12 & 1 & 1 & 1.08 \\
\hline Stichopus chloronotus & 0.354 & 1.17 & 108 & 0.128 & 0.262 & 2.25 \\
\hline \multicolumn{7}{|l|}{ Deep habitat } \\
\hline Total holothurians & 0.002 & 1.30 & - & - & - & 1.15 \\
\hline Holothuria fuscogilva & 0.029 & 4.49 & - & - & - & 4.25 \\
\hline H. fuscogilva size & 0.923 & 0.88 & $\complement^{d}$ & 0.947 & 1 & 1.19 \\
\hline H. fuscopunctata size & 0.664 & 0.99 & $\smile^{d}$ & 1 & 1 & 1.08 \\
\hline
\end{tabular}

${ }^{a}$ Observed ratio $=((\mathrm{MCA} / \mathrm{CA})$ after declaration $) /((\mathrm{MCA} / \mathrm{CA})$ before declaration $), n=3$ times before and after declaration.

${ }^{b}$ Ratio for $1-\beta \geq 0.80=(\mathrm{MCA} / \mathrm{CA}$ before declaration $) \times$ iteration to achieve required power.

${ }^{c}$ Power calculation based on potential decrease in the MCA relative to the control areas.

${ }^{d}$ Not determined because observed ratio $<1$. 
tained within a rigorous experimental framework. Recent reviews (Russ 2002; Willis et al. 2003; Sale et al. 2005) suggest that there has not been enough emphasis on this. The use of impact assessment methods provides one such approach by helping managers and communities to understand the complexities of managing marine resources.

\section{Acknowledgments}

This project was commissioned through the Great Barrier Reef Marine Park Authority and funded by the Australian Centre for International Agricultural Research. The Nature Conservancy facilitated establishment of the MCA and trained and supported Conservation Officers with assistance from the South Pacific Regional Environmental Program. The Ministry of Forests, Environment and Conservation and the Department of Fisheries and Marine Resources, The Nature Conservancy, and The WorldFish Center, particularly Peter Ramohia, Moses Biliki, Nelson Kile, Ed Mayer, George Meyer, and Rayner Pitt, provided support. A.J. Underwood and T.M. Glasby gave statistical advice. This is WorldFish Center Contribution No. 1575.

\section{References}

Andrew, N.L., and MacDiarmid, A. 1991. Interactions between sea urchins and spiny lobsters in northeastern New Zealand. Mar. Ecol. Prog. Ser. 70: 211-222.

Bergin, T. 1993. Marine and estuarine protected areas (MEPAs) where did Australia get it wrong? In Protection of Marine and Estuarine Areas - a Challenge for Australians: Proceedings of the 4th Fenner Conference on the Environment, 9-11 October 1991, Canberra, Australia. Edited by A.M. Ivanovici, D. Tarte, and M. Olson. Australian Committee for IUCN, Canberra. pp. 148-155.

Bohnsack, J.A. 1998. Application of marine reserves to reef fisheries management. Aust. J. Ecol. 23: 298-304.

Campbell, R.A., Mapstone, B.D., and Smith, A.D.M. 2001. Evaluating large scale experimental designs for management of coral trout on the Great Barrier Reef, Australia. Ecol. Appl. 11: 17631777.

Carr, M.H., and Reed, D.C. 1993. Conceptual issues relevant to marine harvest refuges: examples from temperate reef fishes. Can. J. Fish. Aquat. Sci. 50: 2019-2028.

Conand, C. 1986. Les resources halieutiques des pays insulaires du Pacifique. Deuxieme partie: Les holothuries. FAO Fisheries Technical Paper No. 272.2. Food and Agricultural Organisation, Rome, Italy.

Dugan, J.E., and Davis, G.E. 1993. Applications of marine refugia to coastal fisheries management. Can. J. Fish. Aquat. Sci. 50: 2029-2042.

Eberhardt, L.L. 1976. Quantitative ecology and impact assessment. J. Environ. Manag. 4: 27-70.

Edgar, G.J., and Barrett, N.S. 1997. Short term monitoring of biotic change in Tasmanian marine reserves. J. Exp. Mar. Biol. Ecol. 213: 261-279.

Garcia-Charton, J.A., and Perez-Ruzafa, A. 1999. Ecological heterogeneity and the evaluation of the effects of marine reserves. Fish. Res. 42: 1-20.

Green, R.H. 1993. Application of repeated measures designs in environmental impact and monitoring studies. Aust. J. Ecol. 18: 81-98.
Halpern, B.S., Gaines, S.D., and Warner, R.R. 2004. Confounding effects of the export of production and the displacement of fishing effort from marine reserves. Ecol. Appl. 14: 1248-1256.

Hilborn, R., Stokes, K., Maguire, J.J., Smith, T., Botsford, L.W., Mangel, M., Orensanz, J., Parma, A., Rice, J., Bell, J., Cochrane, K.L., Garcia, S., Hall, S.J., Kirkwood, G.P., Sainsbury, K., Stefansson, G., and Walters, C. 2004. When can marine reserve areas improve fisheries management? Ocean Coast. Manag. 47: 197-205.

Keough, M.J., and Mapstone, B.D. 1997. Designing environmental monitoring for pulp mills in Australia. Water Sci. Technol. 35: 397-404.

Lincoln-Smith, M.P., Bell, J.D., and Mapstone, B.D. 1997. Testing the use of a marine protected area to restore and manage invertebrate fisheries at the Arnavon Islands, Solomon Islands: choice of methods and preliminary results. Proc. 8th Int. Coral. Reef. Symp. (Panama), 2: 1937-1942.

Long, B., and Skewes, T. 1997. Distribution and abundance of beche-de-mer on Torres Strait reefs. South Pac. Comm. (SPC) Beche-de-mer Information Bull. 9: 17-22.

Long, B.G., Poiner, I.R., and Harris, A.N.M. 1993. Method of estimating the standing stock of Trochus niloticus incorporating Landsat satellite data, with application to the trochus resources of the Bourke Isles, Torres Strait, Australia. Mar. Biol. 115: 587-593.

Mapstone, B.D. 1995. Scalable decision rules in environmental impact assessment: effect size, Type I, and Type II errors. Ecol. Appl. 5(2): 401-410.

McClanahan, T.R., and Arthur, R. 2001. The effect of marine reserves and habitat on populations of east African coral reef fishes. Ecol. Appl. 11: 559-569.

Mercier, A., Battaglene, S.C., and Hamel, J.F. 2000. Settlement preferences and early migration of the tropical sea cucumber Holothuria scabra. J. Exp. Mar. Biol. Ecol. 249: 89-110.

Nash, W. 1993. Trochus. In Nearshore marine resources of the South Pacific. Edited by A. Wright and L. Hill. Forum Fisheries Agency and Institute of Pacific Studies, Honiara, Solomon Islands and Suva, Fiji. pp. 451-496.

Nash, W.J., Tuara, P., Terekia, O., Munro, D., Amos, M., Legata, J., Mataiti, N., Teopa, M., Whitford, J., and Adams, T. 1995. The Aitutaki trochus fishery: a case study. South Pacific Commission Inshore Fisheries Research Project Technical Document No. 9. South Pacific Commission, Noumea, New Caledonia.

Osenberg, C.W., Schmitt, R.J., Holbrook, S.J., Abu-Saba, K.E., and Flegal, A.R. 1994. Detection of environmental impacts: natural variability, effect size and power analysis. Ecol. Appl. 4: 16-30.

Parrish, R. 1999. Marine reserves for fisheries management: why not. Calif. Coop. Ocean Fish. Invest. Rep. 40: 77-86.

Preston, G., and Lokani, P. 1990. Report of a survey of the sea cucumber resources of Ha'apai, Tonga, June 1990. South Pacific Commission, Noumea, New Caledonia.

Reichenbach, N. 1999. Ecology and fishery biology of Holothuria fuscogilva (Echinodermata: Holothuroidea) in the Maldives, Indian Ocean. Bull. Mar. Sci. 64: 103-113.

Richards, A.H., Bell, L.J., and Bell, J.D. 1994. Inshore fisheries resources of Solomon Islands. Mar. Poll. Bull. 29: 90-98.

Roberts, C.M., and Polunin, V.C. 1991. Are marine reserves effective in management of reef fisheries? Rev. Fish Biol. Fish. 1: 65-91.

Roberts, C.M., and Polunin, V.C. 1993. Marine reserves: simple solutions to managing complex fisheries? Ambio, 22: 363-368. 
Roberts, D.E., Smith, A.K., Ajani, P., and Davis, A.R. 1998. Rapid changes in encrusting marine assemblages exposed to anthropogenic point-source pollution: a 'Beyond BACI' approach. Mar. Ecol. Prog. Ser. 163: 213-224.

Russ, G.R. 2002. Yet another review of marine reserves as reef fishery management tools. In Coral reef fishes, dynamics and diversity in a complex ecosystem. Edited by P.F. Sale. Academic Press (Elsevier Science), San Diego, Calif. pp. 421-443.

Sale, P.F., Cowen, R.K., Danilowicz, B.S., Jones, G.P., Kritzer, J.P., Lindeman, K.C., Planes, S., Polunin, N.V.C., Russ, G.R., Sadovy, Y.J., and Steneck, R.S. 2005. Critical science gaps impede use of no-take fishery reserves. Trends Ecol. Evol. 20: 74-80.

Schroeter, S.C., Dixon, J.D., Kastendiek, J., and Smith, R.O. 1993. Detecting the ecological effects of environmental impacts: a case study of kelp forest invertebrates. Ecol. Appl. 3: 331-350.

Schroeter, S.C., Reed, D.C., Kushner, D.J., Estes, J.A., and Ono, D.S. 2001. The use of marine reserves in evaluating the dive fishery for the warty sea cucumber (Parastichopus parvimensis) in California, U.S.A. Can. J. Fish. Aquat. Sci. 58: 1773-1781.

Shelley, C. 1985. Growth of Actinopyga echinites and Holothuria scabra (Holothuroidea: Echinodermata) and their fisheries potential (as beche-de-mer) in Papua New Guinea. Proc. 5th Int. Coral Reef Congr. Tahiti, 5: 297-302.

Stewart-Oaten, A., and Bence, J. R. 2001. Temporal and spatial variation in environmental impact assessment. Ecol. Monogr. 71: 305-339.
Tegner, M.J. 1993. Southern California abalones: can stocks be rebuilt using marine harvest refugia? Can. J. Fish. Aquat. Sci. 50: 2010-2018.

Underwood, A.J. 1992. Beyond-BACI: the detection of environmental impacts on populations in the real, but variable world. J. Exp. Mar. Biol. Ecol. 161: 145-178.

Underwood, A.J. 1993. The mechanics of spatially replicated sampling programmes to detect environmental impacts in a variable world. Aust. J. Ecol. 18: 99-116.

Underwood, A.J. 1997. Experiments in ecology: their logical design and interpretation using analysis of variance. Cambridge University Press, Cambridge, UK.

Underwood, A.J., and Chapman, M.G. 2003. Power, precaution, Type II error and sampling design in assessment of environmental impacts. J. Exp. Mar. Biol. Ecol. 296: 49-70.

Uthicke, S., Welch, D., and Benzie, J.A.H. 2004. Slow growth and lack of recovery in overfished holothurians on the Great Barrier Reef: evidence from DNA fingerprints and repeated large-scale surveys. Conserv. Biol. 18: 1395-1404.

Willis, T.J., Millar, R.B., Babcock, R.C., and Tolimieri, N. 2003. Burdens of evidence and the benefits of marine reserves: putting Descartes before des horse? Environ. Conserv. 30: 97-103. 